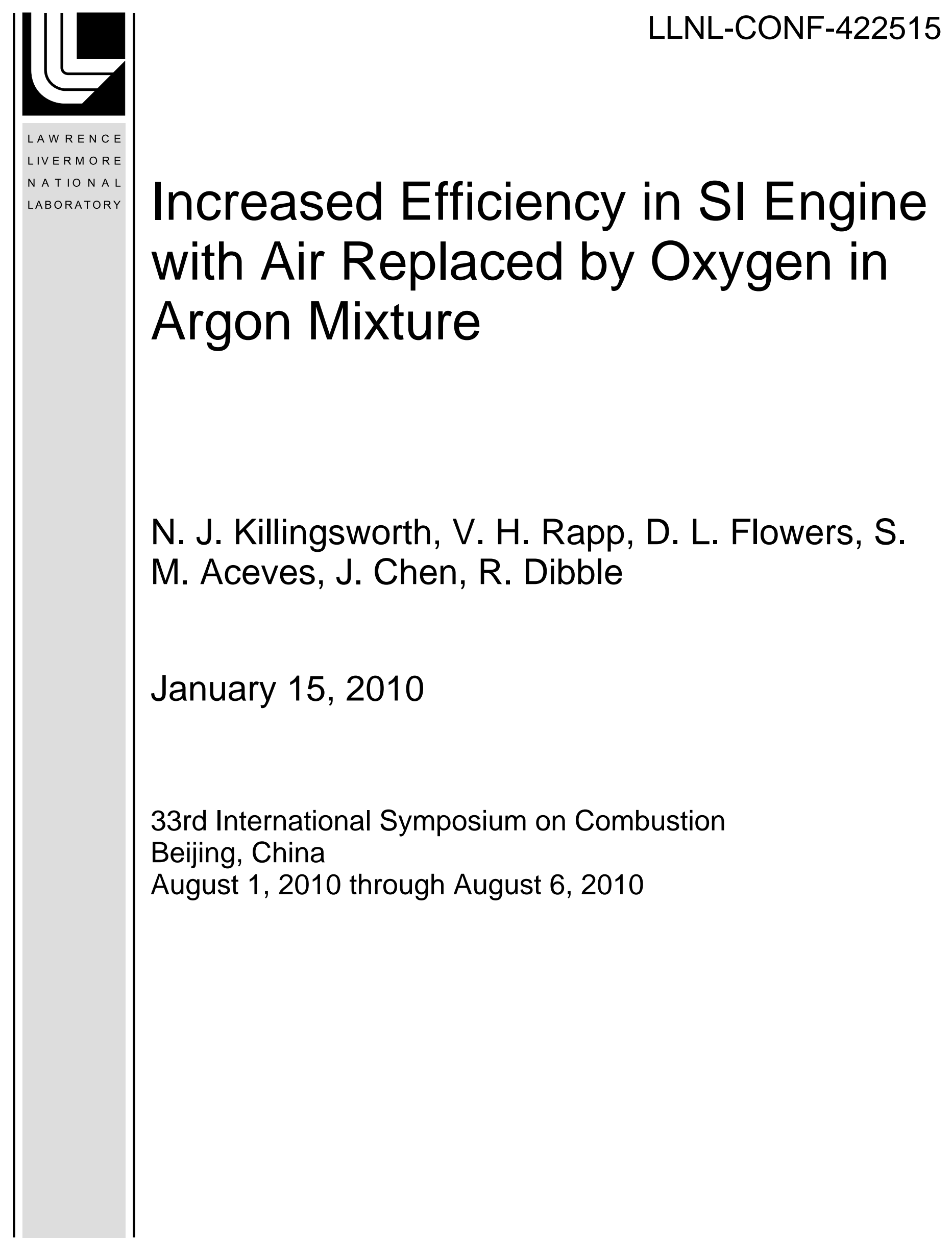


This document was prepared as an account of work sponsored by an agency of the United States government. Neither the United States government nor Lawrence Livermore National Security, LLC, nor any of their employees makes any warranty, expressed or implied, or assumes any legal liability or responsibility for the accuracy, completeness, or usefulness of any information, apparatus, product, or process disclosed, or represents that its use would not infringe privately owned rights. Reference herein to any specific commercial product, process, or service by trade name, trademark, manufacturer, or otherwise does not necessarily constitute or imply its endorsement, recommendation, or favoring by the United States government or Lawrence Livermore National Security, LLC. The views and opinions of authors expressed herein do not necessarily state or reflect those of the United States government or Lawrence Livermore National Security, LLC, and shall not be used for advertising or product endorsement purposes. 


\title{
Increased Efficiency in SI Engine with Air Replaced by Oxygen in Argon Mixture
}

\author{
Nick J. Killingsworth ${ }^{\mathrm{a}}$, Vi H. Rapp ${ }^{\mathrm{b}}$, Daniel L. Flowers ${ }^{\mathrm{a}}$, Salvador M. Aceves ${ }^{\mathrm{a}}$ \\ J-Y. Chen ${ }^{\mathrm{b}}$, and Robert Dibble ${ }^{\mathrm{b}}$ \\ ${ }^{a}$ Lawrence Livermore National Laboratory, Livermore, CA 94550 USA \\ ${ }^{\mathrm{b}}$ Department of Mechanical Engineering, University of California-Berkeley, Berkeley, CA \\ 94720 USA \\ Corresponding author: Nick Killingsworth \\ Lawrence Livermore National Laboratory \\ 7000 East Avenue, L-792 \\ Livermore, CA 94550, USA \\ Phone: (925) 422-8489 \\ Fax: (925) 423-7914 \\ E-mail: killingsworth2@llnl.gov
}

W O R D C O U N T

(Determined by Method 1)

\begin{tabular}{|l|r|}
\hline Text (counted by MS Word) & 3577 \\
Nomenclature & 38 \\
References & 280 \\
Equations & 157 \\
Figures & 1142 \\
Tables & 555 \\
\hline Abstract (not included in Total) & 241 \\
\hline \multicolumn{2}{|c|}{ Total } \\
\hline
\end{tabular}

Submitted for Oral Presentation and Publication at the $33^{\text {rd }}$ International Symposium on Combustion

Tsinghua University, Beijing, China, August 1-6, 2010

In colloquium on IC ENGINE AND GAS TURBINE COMBUSTION 


\begin{abstract}
Basic engine thermodynamics predicts that spark ignited engine efficiency is a function of both the compression ratio of the engine and the specific heat ratio of the working fluid. In practice the compression ratio of the engine is often limited due to knock. Both higher specific heat ratio and higher compression ratio lead to higher end gas temperatures and increase the likelihood of knock. In actual engine cycles, heat transfer losses increase at higher compression ratios and limit efficiency even when the knock limit is not reached. In this paper we investigate the role of both the compression ratio and the specific heat ratio on engine efficiency by conducting experiments comparing operation of a single-cylinder variable-compression-ratio engine with both hydrogen-air and hydrogen-oxygen-argon mixtures. For low load operation it is found that the hydrogen-oxygen-argon mixtures result in higher indicated thermal efficiencies. Peak efficiency for the hydrogen-oxygen-argon mixtures is found at compression ratio 5.5 whereas for the hydrogen-air mixture with an equivalence ratio of 0.24 the peak efficiency is found at compression ratio 13. We apply a three-zone model to help explain the effects of specific heat ratio and compression ratio on efficiency. Operation with hydrogen-oxygen-argon mixtures at low loads is more efficient because the lower compression ratio results in a substantially larger portion of the gas to reside in the adiabatic core rather than in the boundary layer and in the crevices, leading to less heat transfer and more complete combustion.
\end{abstract}

Keywords: Hydrogen, Internal Combustion Engine, Noble Gas, Argon 


\section{Introduction}

Reducing emissions of carbon dioxide $\left(\mathrm{CO}_{2}\right)$ has become increasing urgent. Several possible paths exist to achieve $\mathrm{CO}_{2}$ emissions reductions in the transportation sector: increasing efficiency of petroleum fueled engines, increasing use of alternative fuels, and increasing powertrain electrification with batteries or hydrogen fuel cells. While all of these paths hold some degree of promise, the use of renewable hydrogen $\left(\mathrm{H}_{2}\right)$ as a transportation fuel will reduce not only $\mathrm{CO}_{2}$ emissions, but all carbon based emissions, such as, carbon monoxide (CO) and unburned hydrocarbons. Hydrogen fuel cells are efficient and produce no pollution; however, their high cost is a major barrier limiting their introduction to the mass market. $\mathrm{H}_{2}$ fueled internal combustion (IC) engines are a more viable option since they rely on mature IC engine technology. The only harmful engine-out emissions are oxides of nitrogen $\left(\mathrm{NO}_{\mathrm{x}}\right)$, since $\mathrm{CO}_{2}$ and hydrocarbons from oil consumption are negligible in well-tuned engines. Depending on the operating regime, three-way catalysts, $\mathrm{NO}_{\mathrm{x}}$ traps, or ultra lean combustion can efficiently control $\mathrm{NO}_{\mathrm{x}}$ emissions.

A more radical approach to $\mathrm{NO}_{\mathrm{x}}$ control that may also contribute to increased efficiency consists of replacing nitrogen from the air by an optimized diluent. Noble gases such as helium and argon are promising diluents because of their monatomic structure. These gases are nonreactive and have a high specific heat ratio ( $\gamma=1.67$ compared to $\gamma<1.4$ for air) because noble gases have only one mode of energy storage: translational motion. Basic engine cycle thermodynamics predicts that the use of a gas with high specific heat ratio leads to high engine efficiency. The indicated engine efficiency for an ideal Otto cycle can be written as a function of the engine's compression ratio (CR) and the specific heat ratio of in-cylinder gas [1], 


$$
\eta_{i}=1-\frac{1}{C R^{\gamma-1}} .
$$

This relationship between engine efficiency and the specific heat ratio inspired a patent by Laumann et al. [2] in which argon is utilized in an internal combustion (IC) engine. It was proposed that the water from the exhaust would be condensed out and the remaining argon could then be recycled in a closed loop system. This concept was later tested experimentally in a single cylinder spark ignited (SI) Cooperative Fuel Research (CFR) engine by De Boer and Hulet [3]. High efficiency operation was achieved for high concentrations of argon, but knock was a problem at the compression ratios tested, which ranged from 5.5 to 12 . Direct injection compression ignition engines do not suffer from knock and might be a better solution to take advantage of the thermodynamic properties of noble gases. Ikegami et al. [4] experimentally tested this approach and achieved indicated thermal efficiencies close to 50\% using compression ratios between 10 and 16 . The amount of $\mathrm{H}_{2}$ they could inject at higher compression ratios was limited due to the injection pressure of their system. High pressure $\mathrm{H}_{2}$ gas injection is difficult due to the high diffusivity and low lubricity of $\mathrm{H}_{2}$ gas [5]. Therefore, reliable high pressure injection of $\mathrm{H}_{2}$ gas remains an obstacle for the realization of such an engine.

In the near term a low pressure port injection as opposed to a high pressure direct injection approach is more practical; the following arguments are therefore targeted at port fuel injection spark ignited engines. From Eq. (1) it appears we can arbitrarily increase the compression ratio of the engine and $\gamma$ to achieve high efficiency. However, Eq. (1) assumes isentropic compression with constant specific heat ratio from bottom dead center (BDC) at the beginning of the compression process to top dead center (TDC) just before the combustion event [1]. Given these assumptions the following relation is used, 


$$
\frac{T_{T D C}}{T_{B D C}}=\left(\frac{V_{B D C}}{V_{T D C}}\right)^{\gamma-1}=C R^{\gamma-1},
$$

where $\mathrm{T}_{\mathrm{TDC}}$ is the temperature of the in-cylinder gas at TDC corresponding to the motored (without chemical reactions) temperature and $\mathrm{T}_{\mathrm{BDC}}$ is the temperature of the gas at $\mathrm{BDC}$ and $\mathrm{V}_{\mathrm{TDC}}$ and $\mathrm{V}_{\mathrm{BDC}}$ are the cylinder volumes at TDC and BDC, respectively. Substituting Eq. (2) into Eq. (1) we get a relationship for the thermal efficiency for an ideal Otto cycle as a function of temperature,

$$
\eta_{i}=1-\frac{T_{B D C}}{T_{T D C}} .
$$

Note that we can increase the efficiency by either decreasing $\mathrm{T}_{\mathrm{BDC}}$ or increasing $\mathrm{T}_{\mathrm{TDC}}$. Because the end gas temperature is directly related to the motored temperature of the gas at TDC, $\mathrm{T}_{\mathrm{TDC}}$ can be considered representative of the knock propensity of the engine. In practice $\mathrm{T}_{\mathrm{TDC}}$ is typically limited by knock, which effectively limits how much the compression ratio or specific heat ratio can be increased (see Eq. (2)). Therefore, knock often limits the engine's efficiency. This description simply illustrates the tradeoffs between knock, compression ratio, specific heat ratio, and efficiency; in practice knock behavior is far more complicated and depends on additional factors such as engine's geometry (i.e. spark plug location, cylinder shape, bore, location of valves), fuel properties, wall temperatures, and engine speed. The key point is that increasing either compression ratio or specific heat ratio tends to increase indicated efficiency, but also increase the propensity for knock.

Because knock effectively limits the temperature of the in-cylinder gas at TDC it is not obvious that increasing the specific heat ratio of the gas is more beneficial than simply increasing the compression ratio of the engine. In this paper the differences between obtaining high 
efficiency in a $\mathrm{H}_{2}$ fueled SI engine by increasing the compression ratio and increasing the specific heat ratio of the working fluid are investigated. Specifically, $\mathrm{H}_{2}-\mathrm{O}_{2}-\mathrm{Ar}$ mixtures are compared with $\mathrm{H}_{2}$-air mixtures using a variable compression ratio CFR engine.

First we describe the experimental apparatus and tests conducted. Then we present and discuss the experimental results. We finally present a three-zone model of SI combustion to further interpret the experimental results.

\section{Experimental Apparatus and Data Acquisition}

Experiments were conducted using a single cylinder, port fuel injected, variable compression ratio, ASTM-CFR engine. Engine specifications can be found in Table 1 and a schematic of the experimental configuration is shown in Fig. 1.

In-cylinder pressure was measured using a 6052B Kistler piezoelectric pressure transducer in conjunction with a 5044A Kistler charge amplifier. Intake pressure was measured using a 4045A5 Kistler piezoresistive pressure transducer in conjunction with a 4643 Kistler amplifier module. Sampling of in-cylinder and intake pressures was hardware timed using an optical encoder, and recorded every 0.1 crank angle (CA) degree. An electric motor directly coupled to the engine crankshaft was controlled by an $\mathrm{ABB}$ variable speed frequency drive that in turn controlled the engine speed. Mass of $\mathrm{H}_{2}$ injected was measured using a mass flow sensor (Alicat M Series Mass Flow Meter) and also verified using a Horiba six-gas emissions analyzer. When operating at stoichiometric conditions, $\varphi=1$, a wide band lambda sensor was primarily used. 
Three sets of high-pressure gas cylinders were used: one containing pure Ar, the second with a mixture of $\mathrm{O}_{2}$ and $\mathrm{Ar}$, and the third with pure $\mathrm{H}_{2}$ supplied the engine at specifiable ratios. Pure $\mathrm{O}_{2}$ could be blended with $\mathrm{Ar}$, for safety reasons, we use $\mathrm{O}_{2}$ premixed with $\mathrm{Ar}$, which was then blended with Ar. Flow rates of compressed $\mathrm{Ar}$ and $\mathrm{Ar}-\mathrm{O}_{2}$ were determined using calibrated sonic orifices. Software controlled electronic pressure regulators set the flow rates by adjusting the gas pressure upstream of the sonic orifices.

A Motec M4 ECU (Engine Control Unit) controlled spark timing, injection timing, and injection pulse width. Initially, when running the engine on $\mathrm{H}_{2}$-air mixtures, significant problems with backflash (ignition of the fuel before the intake valve closes) occurred. It was found that the backflash occurred because of residual charge in the spark plug wire created from the previous cycle's ignition [6]. Backflash problems ceased after the spark plug wires in our system were modified as described by Kondo et al. [6].

All tests were conducted without throttling the engine at constant intake pressure of 0.98 bar. The engine was pre-heated by burning $\mathrm{H}_{2}$-air, bringing the coolant temperature to $75^{\circ} \mathrm{C}$. This temperature was maintained for the recorded tests using a closed-loop controller. The crankcase was purged with nitrogen $\left(\mathrm{N}_{2}\right)$, preventing accidental explosion of any hydrogen that might have blown by the rings.

\section{Experimental Results}

We first present results from running the CFR engine on $\mathrm{H}_{2}-\mathrm{O}_{2}-\mathrm{Ar}$ mixtures at various $\mathrm{Ar}$ concentrations and compression ratios. We then compare these results to operation with $\mathrm{H}_{2}$-air at various compression ratios. 


\subsection{Operation with $\mathrm{H}_{2}-\mathrm{O}_{2}-\mathrm{Ar}$}

We investigate the $\mathrm{H}_{2}-\mathrm{O}_{2}-\mathrm{Ar}$ engine concept with a stoichiometric equivalence ratio $(\varphi=1)$. The concentration of Ar is used to alter the power produced by the engine (intake pressure is held constant; therefore, increasing the Ar fraction decreases the $\mathrm{O}_{2}$ fraction, and thus, amount of the $\mathrm{H}_{2}-\mathrm{O}_{2}$ mixture, reducing power). Previous experiments showed that high Ar concentrations resulted in the highest efficiency [3], leading us to look at Ar concentrations of $84 \%, 86 \%$ and $88 \%$ by volume (with the balance being a stochiometric mixture of $\mathrm{H}_{2}$ and $\mathrm{O}_{2}$ ). The composition of the three blends is listed in Table 2. For each blend the compression ratio is varied from 4.5 to 7, in increments of one half. Compression ratios higher than 7 sporadically result in autoignition of the mixture before the spark fired, and they are therefore not reported. The spark timing is swept at each combination of Ar concentration and compression ratio, and we report the spark timing that produces the maximum brake torque. Knock occurs at advanced spark timing with almost all combinations of Ar concentration and compression ratio. Typically we found that the torque increases with advancing spark timing, but advance is limited by the onset of knock.

The net indicated thermal efficiency is plotted versus compression ratio for the three Ar concentrations in Fig. 2. For most operating points Ar concentration of $86 \%$ by volume results in the highest efficiency, then $88 \%$ Ar has the next highest efficiency, and $84 \%$ Ar typically results in the lowest efficiency. For all three blends of $\mathrm{Ar}$ with $\mathrm{O}_{2}$, the peak efficiency occurs at compression ratio 5.5. The overall highest net indicated thermal efficiency achieved is $44.8 \%$ for an Ar concentration of $86 \%$ at compression ratio 5.5 . 
Tables 3 to 5 present performance metrics calculated using the in-cylinder pressure trace for the three $\mathrm{H}_{2}-\mathrm{O}_{2}-\mathrm{Ar}$ blends. The indicated mean effective pressure (IMEP) is defined as the work per engine cycle divided by the displacement and allows engine performance comparison over a range of sizes and speeds. The tables present the IMEP averaged over 300 engine cycles (IMEP ave). Table 3 shows that $84 \%$ Ar concentration has the highest IMEP ${ }_{\text {ave }}$ because this blend has the most fuel of the three blends (Table 2).

The cyclic variability of the operating point is quantified using the coefficient of variation in IMEP ( $\left.\mathrm{COV}_{\text {IMEP }}\right)$ and is defined as the standard deviation in IMEP from cycle-to-cycle over 300 cycles divided by the mean IMEP and multiplied by 100 to yield a percent. From Table 3 we can see that $\mathrm{COV}_{\text {IMEP }}$ increases with compression ratio, because spark timing is simultaneously being delayed to avoid knock. The crank angle at which 50\% of the fuel energy has been released, CA50 (fourth column in Tables 3-6), similarly illustrates the trend of delaying the combustion process to avoid knock with increasing compression ratio. If knock were not occurring, more spark timing advance and lower $\mathrm{COV}_{\text {IMEP }}$ could be achieved for some compression ratios.

The last three columns of the table describe the burning process. The crank angle interval from initiation of the spark to the crank angle at which $10 \%$ of the fuel energy has been released, CA10-CA0, describes the early flame development period. CA90-CA10 is the crank angle interval required to burn the bulk of the fuel and is the difference between the crank angle at which $90 \%$ and $10 \%$ of the fuel energy has been released, CA90 and CA10 respectively. Finally, CA90-CA0 defines the overall burning process and is the crank angle interval between spark plug firing and $90 \%$ of the fuel energy being released. Figures 3 to 5 graphically show the 
burning process for the three blends of $\mathrm{H}_{2}, \mathrm{O}_{2}$ and Ar. These plots display the crank angle location of spark ignition, and the crank angles at which $10 \%, 50 \%$, and $90 \%$ of the fuel energy has been released. The trend of delaying spark timing with increasing compression ratio can clearly been seen in these plots. For an Ar concentration of $84 \%$ the duration of the early flame development CA10-CA0 decreases with increasing compression ratio; however, the duration of the bulk combustion CA90-CA10 is fairly constant with changes to the compression ratio and it is only lengthened for the highest compression ratio due to the very late spark timing. These trends also hold for Ar concentrations of $86 \%$ and $88 \%$. The compression temperature increases with compression ratio and the increased temperature leads to higher flame speeds during the initial flame development period, as will be discussed in more detail in the modeling.

Considering the advances in engine technology that have occurred since the CFR engine was designed, the low engine speed tested here, and that the CFR engine was designed specifically to knock it is expected that the efficiency of this concept could be further improved using a modern engine that is less prone to knock. Furthermore, increasing the combustion rate with advanced ignition systems $[7,8]$ could be used to extend the knock limit. Direct injection compression ignition is also a promising route to achieve higher efficiencies if the injectors can be made more reliable.

\subsection{Operation with $\mathrm{H}_{2}$-air}

For comparison, the engine is also operated with $\mathrm{H}_{2}$-air mixtures. We chose an equivalence ratio of 0.24 because this mixture requires the same mass of $\mathrm{H}_{2}$ as used for $\mathrm{H}_{2}-\mathrm{O}_{2}-\mathrm{Ar}$ mixtures with $86 \%$ Ar. The compression ratio is varied from 6 to 17 and the spark timing is swept at each compression ratio. We report the spark timing that produced the maximum brake torque. We can see by comparing Tables 6 and 4 that the overall burn duration CA90-CA0 is substantially longer 
for the $\mathrm{H}_{2}$-air mixture than for all the $\mathrm{H}_{2}-\mathrm{O}_{2}$-Ar mixtures. Both the early flame development interval CA10-CA0 and the bulk burn interval CA90-CA10 are between one and a half to two times longer than the $86 \% \mathrm{Ar}$ mixture. $\mathrm{H}_{2}$-air flame speed is very sensitive to temperature and this is likely the reason for the difference. The burn behavior of $\mathrm{H}_{2}$-air does not change much with compression ratio as can also be seen in Fig. 6.

Figure 7 shows the net indicated thermal efficiency plotted versus compression ratio. From this plot we can see that the efficiency is much lower than for the $\mathrm{H}_{2}-\mathrm{O}_{2}-\mathrm{Ar}$ mixtures. The efficiency initially increases as the compression ratio is increased from 6, but then quickly levels out and peaks at a compression ratio of 13 to $35.9 \%$ and then decreases. Heat transfer becomes increasingly important as the compression ratio is increased and has the effect of reducing engine efficiency.

\section{Three-Zone SI Combustion Model}

A three-zone model, consisting of a burned zone, unburned zone, and crevices, is used to model combustion in the CFR engine. Because the CFR engine is port fuel injected, the air and fuel are assumed to be perfectly mixed. During the compression stroke, the combustible mixture flows into the crevices. The gas pressure is assumed uniform in all zones such that the mass exchange rate between the zones can be solved simultaneously with energy and species equations $[9,10]$. The combustion process is divided into two stages. The first stage is the ignition and initiation of the three zones in combustion space. The second stage is the propagation of the flame front. Once a small nucleus of the fuel-air mixture has combusted, the combustion chamber is subdivided into two zones. Following spark ignition, there is a delay period that is modeled empirically [11]. Once combustion has commenced, the mean burned gas front is approximated by a sphere centered on the spark plug location. The burning rate is 
modeled as the product of the spherical burning area and the turbulent burning rate [1]. Heat transfer between the gases in all three zones and the cylinder walls at a rate proportional to the chamber surface area wetted by the gases is modeled using the Woschni correlation [12]. During the expansion stroke, unburned gases stored in the crevices flow back into the combustion chamber accounting for unburned fuel produced in the experiment. Intake and exhaust flows are modeled using measured valve lifts. The mass flows through the intake and exhaust valves are modeled with a discharge coefficient $C_{d}=0.6$. The effect of residual burned gas from previous cycles is included by running the model through eight complete cycles.

\subsection{Details of model}

The turbulent burning rate is computed as [1]

$$
\frac{d m_{b}}{d t}=\rho_{u} \cdot A_{f} \cdot S_{T}
$$

where $m_{b}$ denotes the mass of burned mixture, $S_{T}$ is the turbulent flame speed, $\rho_{u}$ and $A_{f}$ are the unburned density and flame surface area, respectively.

An empirical model is used for the turbulent flame speed,

$$
S_{T}=S_{L} \cdot f \cdot \frac{\rho_{u} / \rho_{b}}{\left(\rho_{u} / \rho_{b}-1\right) \cdot Y_{m b}+1},
$$

where $S_{L}$ is the laminar flame speed, $f=1+0.0018 \cdot \mathrm{RPM}$ is the turbulent enhancement factor, $Y_{m b}$ is the mass fraction of burned mixture, $\rho_{b}$ is the density of burned mixture. The laminar flame speed is computed as 


$$
S_{L}=S_{L 0}\left(\frac{T}{T_{\text {ref }}}\right)^{\alpha}\left(\frac{p}{p_{\text {ref }}}\right)^{\beta}(\mathrm{cm} / \mathrm{s}) .
$$

where $T$ and $p$ are the temperature and pressure, $T_{\text {ref }}$ and $p_{\text {ref }}$ are the reference temperature and pressure, and the parameters $S_{L 0}, \alpha$, and $\beta$ can be found in Table 8 .

\subsection{Model Results and Discussion}

Given equation (3) it may be expected that similar efficiencies could be achieved by operating the engine with $\mathrm{H}_{2}-\mathrm{O}_{2}$ - $\mathrm{Ar}$ and $\mathrm{H}_{2}$-air mixtures when the same mass of fuel and compression ratios that resulted in similar motored temperatures at TDC were used; however, as shown in Fig. 7 the efficiencies are not the same. This difference is explored using the three zone model; a comparison is made between a $\mathrm{H}_{2}-\mathrm{O}_{2}$ - $\mathrm{Ar}$ mixture and a $\mathrm{H}_{2}$-air mixture with the same mass of fuel and compression ratios that resulted in similar motored temperatures at TDC. We compare blend 2 with $86 \%$ Ar concentration by volume to an $\mathrm{H}_{2}$-air mixture with $\varphi=0.24$. The motored temperature at TDC for the $\mathrm{H}_{2}-\mathrm{O}_{2}$-Ar mixture with a compression ratio of 6 and the $\mathrm{H}_{2}$-air mixture with a compression ratio of 16 are both about $900 \mathrm{~K}$, Eq. (3) therefore predicts equal thermal efficiencies.

Figure 8 shows the modeling results. Pressure traces are displayed in (a) for the two conditions, both from the model and experiments. The model results compare well with the experimental pressure, giving us reason to trust the other outputs from the model. The magnitude of the pressure for the two mixtures is quite different; peak pressure for the $\mathrm{H}_{2}$-air mixture is almost 45 bar, whereas peak pressure for the $\mathrm{H}_{2}-\mathrm{O}_{2}-\mathrm{Ar}$ mixture is around 20 bar. The peak pressure has implications on how robust the engine must be since the pressure exerts force on the engine components. 
Figure 8 (b) and (c) present the temperatures of the three zones in the model: burned, unburned, and crevices versus crank angle degree; as well as the net heat release for the $\mathrm{H}_{2}-\mathrm{O}_{2}$ Ar mixture and $\mathrm{H}_{2}$-air mixture, respectively. Comparing plots (b) and (c) we can see that the burned gas temperature is much higher for the $\mathrm{H}_{2}-\mathrm{O}_{2}$-Ar mixture; in large part because the heat capacity is much lower for this mixture and the fuel's chemical energy raises the mixtures temperature more than for the $\mathrm{H}_{2}$-air mixture. From Eqs. (5) and (6) we can see that the flame speed is very sensitive to temperature, which helps explain the differences in burn duration between the two mixtures as shown in Tables 4 and 6 and Figs. 4 and 6. The model also predicts that about $6 \%$ of the hydrogen (by mass) remains unburned for the $\mathrm{H}_{2}$-air mixture due to the large mass in the cold crevices. The amount of gas in the crevices for the $\mathrm{H}_{2}$-air mixture is substantially larger because of the high compression ratio. We can see from plots (b) and (c) that the net heat release is lower for the $\mathrm{H}_{2}$-air mixture because of the difference in the amount of unburned fuel. Tang et al. [13] swept the equivalence ratio in a $\mathrm{H}_{2}$-air SI engine and found that the indicated efficiency dropped off at $\phi=0.22$ due to increases in unburned hydrogen and increased burn duration. Another effect likely important for the experiments is that the highest rates of heat transfer occur in the boundary layer close to the wall, and due to the high compression ratio used for the $\mathrm{H}_{2}$-air mixture a larger portion of the mixture resides within the boundary layer, therefore higher heat transfer rates are expected [14].

\section{Conclusions}

- A Compression ratio of 5.5 is the most efficient for each of the three $\mathrm{H}_{2}-\mathrm{O}_{2}$-Ar blends tested. Peak net indicated thermal efficiency (44.8\%) occurred with a dilution level of 86\% Ar and compression ratio 5.5 . 
- For comparison, experiments are conducted with $\mathrm{H}_{2}$-air at an equivalence ratio of 0.24. Peak net indicated thermal efficiency of $35.9 \%$ is reached at compression ratio 13 , which is substantially lower than that of the $\mathrm{H}_{2}-\mathrm{O}_{2}-\mathrm{Ar}$ mixtures tested.

- A three-zone model is used to compare an $\mathrm{H}_{2}-\mathrm{O}_{2}-\mathrm{Ar}$ mixture with an $\mathrm{Ar}$ concentration of $86 \%$ and compression ratio 6 to an $\mathrm{H}_{2}$-air with an equivalence ratio of 0.24 and compression ratio 16, these two mixtures have the same mass of fuel and almost identical peak motoring temperatures. The model predicts that the $\mathrm{H}_{2}$-air mixture has a substantial amount of unburned hydrogen arising from the increased mass residing in the crevices.

\section{Acknowledgments}

This work performed under the auspices of the U.S. Department of Energy by Lawrence Livermore National Laboratory under Contract DE-AC52-07NA27344.

\section{References}

[1] J.B. Heywood, Internal combustion engine fundamentals, New York, McGraw-Hill, 1988.

[2] E.A. Laumann, R.K. Reynolds, Hydrogen-fueled engine, 1978.

[3] P. deBoer, J. Hulet, Performance of a hydrogen-oxygen-noble gas engine, Int. J. Hydrogen Energy. 5 (1980) 439-452.

[4] M. Ikegami, K. Miwa, M. Shioji, A study on hydrogen-fueled compression-ignition engines, Int. J. Hydrogen Energy. (1982) 341-353.

[5] A.B. Welch, D. Mumford, S. Munshi, J. Holbery, B. Boyer, M. Younkins, et al., Challenges in Developing Hydrogen Direct Injection Technology for Internal Combustion Engines, SAE Paper, No. 2008-01-2379. (2008).

[6] T. Kondo, S. Iio, M. Hiruma, A Study on the Mechanism of Backfire in External Mixture Formation Hydrogen Engines, SAE Paper, No. 971704. (1997).

[7] Y. Ikeda, A. Nishiyama, M. Kaneko, Microwave Enhanced Ignition Process for Fuel Mixture at Elevated Pressure of 1MPa, in: 47th AIAA Aerospace Sciences Meeting Including the New Horizons Forum and Aerospace Exposition, 2009.

[8] A.A. Boretti, H.C. Watson, Enhanced combustion by jet ignition in a turbocharged cryogenic port fuel injected hydrogen engine, International Journal of Hydrogen Energy. 34 (2009) 2511-2516.

[9] T. Jensen, J. Schramm, A Three-Zone Heat Release Model for Combustion Analysis in a Natural Gas SI Engine - Effects of Crevices and Cyclic Variation on UHC Emissions, SAE 
Paper, No. 2000-01-2802. (2000).

[10] G. Chin, J. Chen, Development of a Consistent Crevices Model For Multi-Zone Modeling of Piston Engines, in: University of California at Irvine, 2009.

[11] M. Al-Baghdadi, A Simulation Model for a Single Cylinder Four-Stroke Spark Ignition Engine Fueled with Alternative Fuels, Turkish J. Eng. Env. Sci. 30 (2006) 331350.

[12] G. Woschni, A universally applicable equation for instantaneous heat transfer in the internal combustion engine, SAE Paper, No. 670931. (1967).

[13] X. Tang, D.M. Kabat, R.J. Natkin, W.F. Stockhausen, J.W. Heffel, Ford P2000 Hydrogen Engine Dynamometer Development, SAE Paper No. 2002-01-0242. (2002).

[14] J.R. Smith, Optimized hydrogen piston engines, in: 1994 Society of Automotive Engineers' Convergence, 1994. 


\section{Tables}

Table 1

Engine Specifications

\begin{tabular}{ccccc}
\hline Displacement & Bore & Stroke & Compression Ratio & rpm \\
\hline $0.616 \mathrm{~L}$ & $82.5 \mathrm{~mm}$ & $114 \mathrm{~mm}$ & $4.5-17$ & 900 \\
\hline
\end{tabular}

Table 2

Fuel-Oxidizer-Ar Mixture Concentrations by Volume

\begin{tabular}{cccc} 
& $\mathrm{H} 2$ & $\mathrm{O} 2$ & $\mathrm{Ar}$ \\
\hline Blend 1 & $10.67 \%$ & $5.33 \%$ & $84.0 \%$ \\
Blend 2 & $9.33 \%$ & $4.67 \%$ & $86.0 \%$ \\
Blend 3 & $8.00 \%$ & $4.00 \%$ & $88.0 \%$ \\
\hline
\end{tabular}

Table 3

Pressure trace analysis $84 \% \mathrm{Ar}$

\begin{tabular}{ccccccc}
\hline Compression Ratio & IMEP $_{\text {ave }}[\mathrm{bar}]$ & $\mathrm{COV}_{\text {IMEP }}[\%]$ & CA50 & CA10-CA0 & CA90-CA10 & CA90-CA0 \\
\hline 4.5 & 4.1 & 1.1 & 14.3 & 20.4 & 19.5 & 40.0 \\
5.0 & 4.3 & 1.5 & 17.9 & 17.4 & 18.9 & 36.3 \\
5.5 & 4.3 & 1.5 & 22.5 & 15.0 & 19.1 & 34.0 \\
6.0 & 4.2 & 1.6 & 27.9 & 14.5 & 20.3 & 34.8 \\
6.5 & 4.2 & 1.9 & 28.1 & 12.4 & 20.0 & 32.4 \\
7.0 & 3.8 & 2.9 & 40.2 & 13.6 & 25.4 & 39.0 \\
\hline
\end{tabular}

Table 4

Pressure trace analysis $86 \% \mathrm{Ar}$

\begin{tabular}{ccccccc} 
Compression Ratio & IMEP $_{\text {ave }}[\mathrm{bar}]$ & $\mathrm{COV}_{\text {IMEP }}[\%]$ & CA50 & CA10-CA0 & CA90-CA10 & CA90-CA0 \\
\hline 4.5 & 3.8 & 1.0 & 11.8 & 27.8 & 23.5 & 51.4 \\
5.0 & 3.7 & 1.5 & 16.9 & 22.1 & 23.5 & 45.6 \\
5.5 & 3.8 & 1.9 & 20.7 & 19.6 & 24.1 & 43.8 \\
6.0 & 3.5 & 2.3 & 23.8 & 17.0 & 25.9 & 42.8 \\
6.5 & 3.6 & 3.3 & 25.5 & 15.2 & 24.5 & 39.7 \\
7.0 & 3.5 & 3.7 & 33.1 & 14.5 & 30.6 & 45.2 \\
\hline
\end{tabular}

Table 5

Pressure trace analysis 88\% Ar

\begin{tabular}{ccccccc} 
Compression Ratio & IMEP $_{\text {ave }}[\mathrm{bar}]$ & $\mathrm{COV}_{\text {IMEP }}[\%]$ & CA50 & CA10-CA0 & CA90-CA10 & CA90-CA0 \\
\hline 4.5 & 3.0 & 2.0 & 8.5 & 46.9 & 31.2 & 78.1 \\
5.0 & 3.2 & 2.1 & 13.6 & 33.2 & 29.2 & 62.4 \\
5.5 & 3.2 & 2.4 & 18.7 & 26.1 & 30.1 & 56.2 \\
6.0 & 3.0 & 4.4 & 23.4 & 23.0 & 33.0 & 56.0 \\
6.5 & 2.6 & 7.9 & 30.2 & 15.6 & 43.9 & 59.4 \\
4.5 & 3.0 & 2.0 & 8.5 & 46.9 & 31.2 & 78.1 \\
\hline
\end{tabular}


Table 6

Pressure trace analysis $\mathrm{H}_{2}$ air, $\varphi=0.24$

\begin{tabular}{ccccccc}
\hline Compression Ratio & IMEP $_{\text {ave }}[\mathrm{bar}]$ & COV $_{\text {IMEP }}[\%]$ & CA50 & CA10-CA0 & CA90-CA10 & CA90-CA0 \\
\hline 6.0 & 3.2 & 1.8 & 5.7 & 33.8 & 46.5 & 80.2 \\
8.0 & 3.5 & 2.0 & 7.0 & 31.4 & 45.8 & 77.1 \\
10.0 & 3.5 & 2.0 & 8.5 & 30.4 & 47.5 & 77.9 \\
12.0 & 3.5 & 2.1 & 10.2 & 31.2 & 47.6 & 78.8 \\
13.0 & 3.6 & 2.5 & 10.3 & 27.7 & 48.7 & 76.4 \\
14.0 & 3.5 & 2.6 & 15.3 & 27.0 & 49.6 & 76.6 \\
15.0 & 3.5 & 2.8 & 17.0 & 28.5 & 50.3 & 78.9 \\
16.0 & 3.5 & 2.8 & 18.3 & 27.8 & 50.6 & 78.4 \\
17.0 & 3.4 & 3.3 & 20.3 & 30.0 & 50.2 & 80.2 \\
\hline
\end{tabular}

Table 7

Fuel-Oxidizer-Ar Mixture Concentrations by Volume

\begin{tabular}{llll}
\hline Mixture & $\mathrm{S}_{\mathrm{L} 0}$ & $\alpha$ & $\beta$ \\
\hline $\mathrm{H}_{2}-\mathrm{Ar} 84 \%$ & 131 & 1.52 & -0.17 \\
$\mathrm{H}_{2}-\mathrm{Ar} 86 \%$ & 92 & 1.52 & -0.17 \\
$\mathrm{H}_{2}-\mathrm{Ar} 88 \%$ & 56 & 1.52 & -0.17 \\
$\mathrm{H}_{2}-\mathrm{Air} \phi=0.24$ & 25.8 & 2.8 & -0.29 \\
\hline
\end{tabular}




\section{Figures}

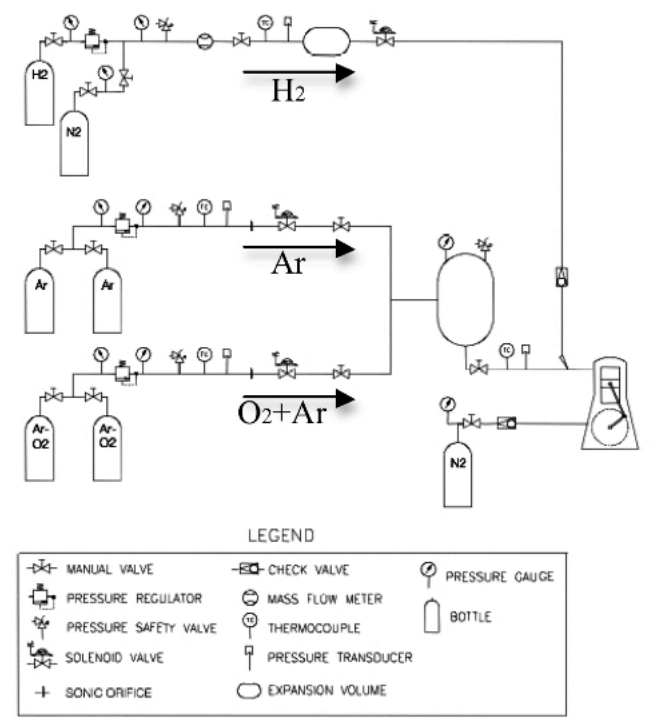

Fig. 1 Schematic diagram of the experimental configuration.

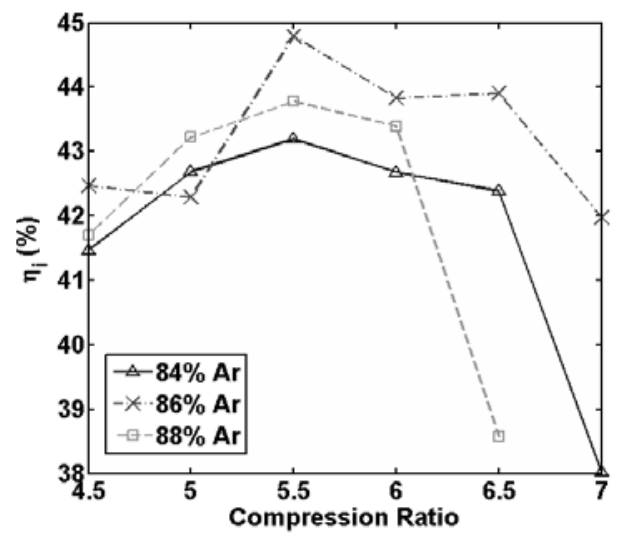

Fig. 2. Indicated thermal efficiency versus compression ratio for the three Ar concentrations. The peak thermal efficiency obtained occurs at a CR of 5.5 for each concentration.

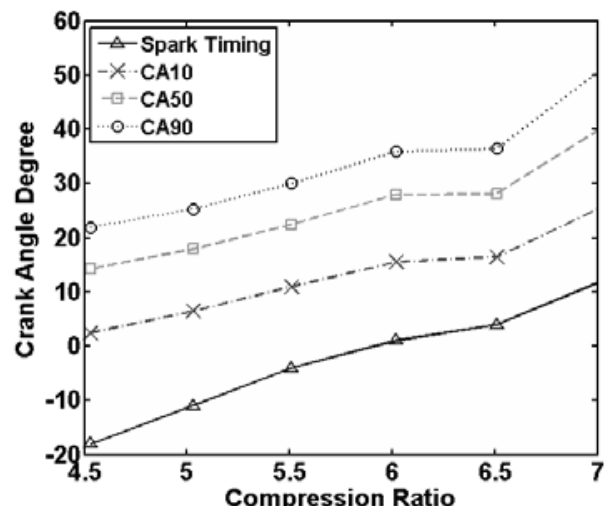

Fig. 3. Evolution of the heat release at each compression ratio for the $\mathrm{H}_{2}-\mathrm{O}_{2}-\mathrm{Ar}$ mixture with $84 \%$ Ar. This plots shows the MBT spark timings, and the crank angle degrees at which $10 \%, 50 \%$, and $90 \%$ of the fuels energy has been released at each compression ratio. 


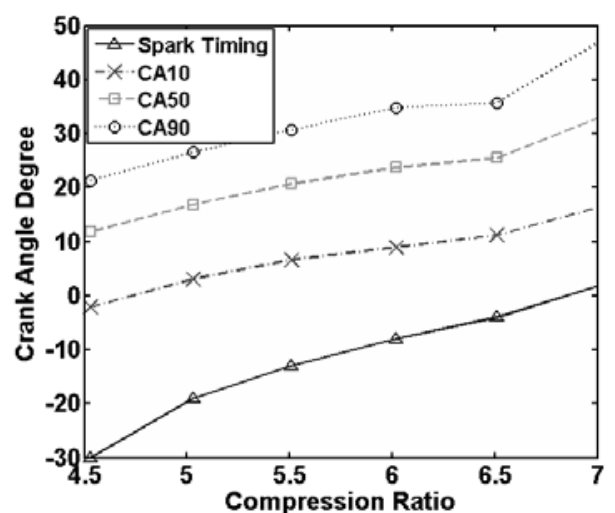

Fig. 4. Evolution of the heat release at each compression ratio for the $\mathrm{H}_{2}-\mathrm{O}_{2}-\mathrm{Ar}$ mixture with $86 \%$ Ar. This plots shows the MBT spark timings, and the crank angle degrees at which $10 \%, 50 \%$, and $90 \%$ of the fuels energy has been released at each compression ratio.

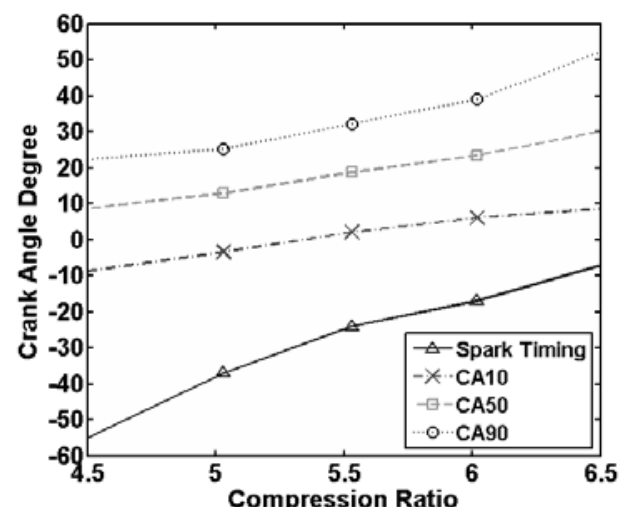

Fig. 5. Evolution of the heat release at each compression ratio for the $\mathrm{H}_{2}-\mathrm{O}_{2}$-Ar mixture with $88 \%$ Ar. This plots shows the MBT spark timings, and the crank angle degrees at which $10 \%, 50 \%$, and $90 \%$ of the fuels energy has been released at each compression ratio.

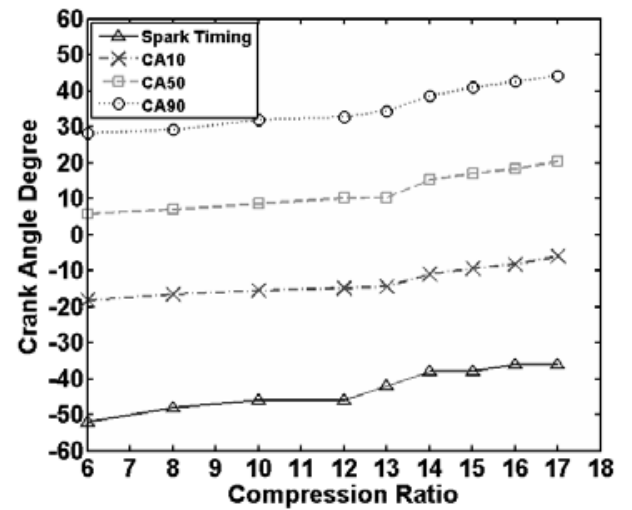

Fig. 6. Evolution of the heat release at each compression ratio for the $\mathrm{H}_{2}$-air mixture with $\varphi=0.24$. This plots shows the MBT spark timings, and the crank angle degrees at which $10 \%, 50 \%$, and $90 \%$ of the fuels energy has been released at each compression ratio. 


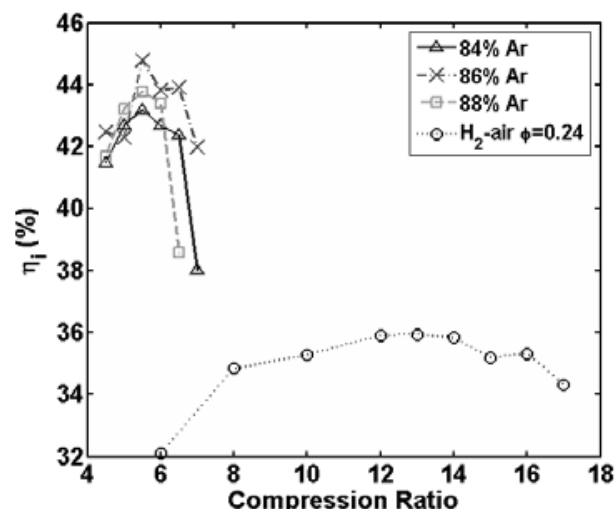

Fig. 7. Indicated thermal efficiency versus compression ratio for $\mathrm{H}_{2}-\mathrm{O}_{2}$-Ar mixtures of $84 \%, 86 \%$, and $88 \%$ Ar concentration and $\mathrm{H}_{2}$-air mixture with $\varphi=0.24$. The peak thermal efficiency obtained for the $\mathrm{H}_{2}$-air mixture is much lower than for the $\mathrm{H}_{2}-\mathrm{O}_{2}$ - $\mathrm{Ar}$ mixtures. 

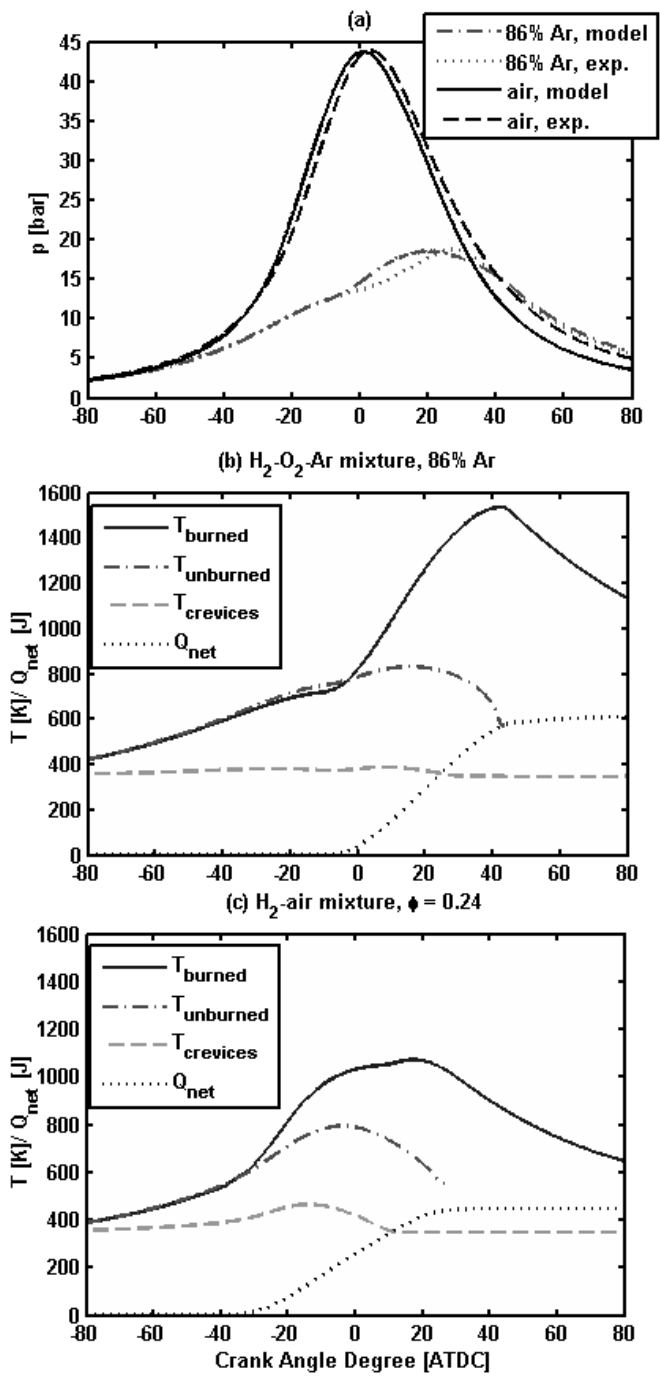

Fig. 8. Modeling comparison between $\mathrm{H}_{2}-\mathrm{O}_{2}$-Ar mixture of $86 \% \mathrm{Ar}$, and $\mathrm{H}_{2}$-air mixture with $\varphi=0.24$. (a) In-cylinder pressure, (b) temperature in burned zone, temperature in unburned zone, temperature in crevices, and cumulative heat release of $86 \%$ Ar mixture with a compression ratio of 6, (c) temperature in burned zone, temperature in unburned zone, temperature in crevices, and cumulative heat release of $\mathrm{H}_{2}$-air mixture with a compression ratio of 16 . 


\section{List of Figure Captions:}

Fig. 3 Schematic diagram of the experimental configuration.

Fig. 4. Indicated thermal efficiency versus compression ratio for the three Ar concentrations. The peak thermal efficiency obtained occurs at a CR of 5.5 for each concentration.

Fig. 3. Evolution of the heat release at each compression ratio for the $\mathrm{H}_{2}-\mathrm{O}_{2}$-Ar mixture with $84 \%$ Ar. This plots shows the MBT spark timings, and the crank angle degrees at which $10 \%, 50 \%$, and $90 \%$ of the fuels energy has been released at each compression ratio.

Fig. 4. Evolution of the heat release at each compression ratio for the $\mathrm{H}_{2}-\mathrm{O}_{2}-\mathrm{Ar}$ mixture with 86\% Ar. This plots shows the MBT spark timings, and the crank angle degrees at which $10 \%, 50 \%$, and $90 \%$ of the fuels energy has been released at each compression ratio.

Fig. 5. Evolution of the heat release at each compression ratio for the $\mathrm{H}_{2}-\mathrm{O}_{2}-\mathrm{Ar}$ mixture with 88\% Ar. This plots shows the MBT spark timings, and the crank angle degrees at which $10 \%, 50 \%$, and $90 \%$ of the fuels energy has been released at each compression ratio.

Fig. 6. Evolution of the heat release at each compression ratio for the $\mathrm{H}_{2}$-air mixture with $\varphi=$ 0.24 . This plots shows the MBT spark timings, and the crank angle degrees at which $10 \%$, $50 \%$, and $90 \%$ of the fuels energy has been released at each compression ratio.

Fig. 7. Indicated thermal efficiency versus compression ratio for $\mathrm{H}_{2}-\mathrm{O}_{2}$-Ar mixtures of $84 \%$, $86 \%$, and $88 \%$ Ar concentration and $\mathrm{H}_{2}$-air mixture with $\varphi=0.24$. The peak thermal efficiency obtained for the $\mathrm{H}_{2}$-air mixture is much lower than for the $\mathrm{H}_{2}-\mathrm{O}_{2}$-Ar mixtures.

Fig. 8. Modeling comparison between $\mathrm{H}_{2}-\mathrm{O}_{2}$-Ar mixture of $86 \% \mathrm{Ar}$, and $\mathrm{H}_{2}$-air mixture with $\varphi=$ 0.24. (a) In-cylinder pressure, (b) temperature in burned zone, temperature in unburned zone, temperature in crevices, and cumulative heat release of $86 \%$ Ar mixture with a compression ratio of 6, (c) temperature in burned zone, temperature in unburned zone, temperature in crevices, and cumulative heat release of $\mathrm{H}_{2}$-air mixture with a compression ratio of 16. 